\title{
Driving Creativity: Extending Knowledge Management into the Multinational Corporation
}

\author{
James W. Gabberty and Jennifer D. E. Thomas \\ Pace University, New York, NY, USA
}

\author{
JGabberty@Pace.edu; JThomas@Pace.edu
}

\begin{abstract}
A major issue facing the multinational corporation (MNC) knowledge management (KM) function is grappling with how information and communications technology (ICT) can best assist in promoting innovation and creativity, shepherding ideas from concept through reality. This paper presents a model in which to examine this development that is designed to promote continued competitiveness in an increasingly interlinked and interdependent global marketplace. The model distinguishes between a tacit knowledge zone (TKZ), a non-binding refinement zone (NRZ), and an explicit knowledge zone (EKZ) and suggests areas for research within the context of this model.
\end{abstract}

Keywords: Knowledge Management, Information \& Communications Technology, Creativity, Innovation, Idea Modeling, Multinational Corporation

\section{Introduction}

As companies strive to achieve competitive advantage, it is imperative for firms to reflect on their historical competitive strengths that initially drove the early creativity processes that sustained their evolution and led to their expansion into overseas markets and global operation centers. By sustaining an environment that promotes the process by which product designers imagine and create new products and services, the same relentless compulsion to question, discover, and make innovations provides firms with the conditions necessary to acquire additional revenues needed to fund strategic directives. If the necessary ICT infrastructure is put into place as firms expand globally, a by-product of the operational logistic and tactical expansion functions will be the coincident enlargement of the firms' ability to innovate. To quote William Blake as cited in Durant-Law (2006), "I must create a system, or be enslaved by another man's. I will not reason and compare; my business is to create". This enhanced environment should allow companies to grow in the context of the cultures and regions they touch, as new ways of looking at products and services become manifest by a more diverse workforce. Hence, by putting into place an informational infrastructure that crosses knowledge boundaries, visualizes results, applies

Material published as part of this publication, either on-line or in print, is copyrighted by the Informing Science Institute. Permission to make digital or paper copy of part or all of these works for personal or classroom use is granted without fee provided that the copies are not made or distributed for profit or commercial advantage AND that copies 1) bear this notice in full and 2) give the full citation on the first page. It is permissible to abstract these works so long as credit is given. To copy in all other cases or to republish or to post on a server or to redistribute to lists requires specific permission and payment of a fee. Contact Publisher@InformingScience.org to request redistribution permission. analogies and embraces failure, the same recipe that allows domestic firms to thrive and flourish will significantly enhance the likelihood of future successes for the MNC.

The paper discusses the deficiencies in the link between knowledge management, creativity and its technological underpinnings, proposes a model for integrating these designed to explore the question of how innovative 
idea creation is realized, developed and channeled in the MNC. Areas for future research stemming from this model and concluding comments pertinent to the consideration of these issues are also articulated.

\section{The Weak Bonds between ICT, KM, and Creativity}

Consider how difficult a task it is to pass on the values, social mores, and other firm-specific characteristics to new-comers, either to the industry or to the firm. How does one hand-off the valuable personal competency of thinking creatively? How do you train someone to brainstorm? Recognizing the intrinsic value of these capabilities and the benefit imparted to the firm by employees capable of creative thinking and knowing how to engage others is not only highly relevant but among the most sought after employee skills among MNCs (Ergazakis, Metaxiotis \& Pearras, 2006; Ford \& Staples, 2006).

Studies identifying the process of how companies approach the arduous task of instituting, maintaining, and improving knowledge management systems designed specifically to enhance firmwide creativity by leveraging information technology assets are sparse, and in some cases contradictory (Cairncross, 2002; Carayannis, 1999; Darroch \& McNaughton, 2002; Knight \& Cavusgil, 2004). Contrastingly, studies highlighting the degree to which firms are strengthening their value chain linkages in order to achieve operational efficiency are numerous (Barry \& Kearney, 2006; Farrell, 2006; Hill, Marino \& Chae, 2003; Kim, Cavusgil \& Calantone, 2006; Kuei, Madu, Chow $\&$ Lu, 2005; Liker \& Morgan, 2006). This difference in available research may be attributed, in part, to the well-documented benefits attributed to value chain improvements assessed by many academics and business practitioners. The fact that these ICT-driven benefits hold the potential of almost immediately impacting the firm through the realization of significant savings from lowered production costs, decreased wages (by way of outsourcing well-defined tasks) and by tightly coupling the inventory supply chain are some of the reasons why such rigorous ICT productivity studies exist (Klein, 2003). Moreover, technology's positive affects as an influencer in driving several of the key processes outlined in the proposed model in this paper is a further contributory factor warranting investigation.

A good example of a company whose value chain has been intensively scrutinized by industry pundits and academics alike is the Dell Corporation. While many firms' revenue growth turned downward immediately after the start of the new millennium, Dell's performance was extraordinary. Much of the firm's rising equity valuation during the period $2001-2005$ has to do with Dell's legendary "inventory turn", attainable by closely linking key suppliers to its supply chain, made possible by heavy ICT investment and development. On the other hand, the intangible aspects associated with creativity are difficult to assess, or, perhaps more importantly, the studies attributing the impact that ICT has on a firm in terms of "soft" factors are not entirely understood (Darroch \& McNaughton, 2002).

Promoting innovation and creativity are likely to lead to intangible benefits such as higher morale and could also benefit the firm by promoting the formation of corporate-wide teams that cut across functional boundaries. The effect of such organizational synergism could well usher in an environment of openness to new ideas, sponsorship and increased enthusiasm by upper levels of management. These examples of intangible or soft factors are qualities that impart benefit to the firm (Cross, Davenport \& Cantrell, 2003). The question thus remains - how does ICT assist the $\mathrm{MNC}$ in promoting innovation and creativity, shepherding ideas from concept through reality?

Irrespective of whether a firm intentionally designs its ICT infrastructure to improve the creative processes within the firm or if creativity is kept entirely out of the systems development process, all systems have the potential to influence (positively or negatively) how well a firm performs in 
coordinating the myriad tasks needed to foster an idea from a spark of enlightenment to a fully functional final product (Hsai, Lin, Wu, \& Tsai, 2006; Kogut \& Zander, 2004).

Getting the right data dispersed firm-wide to those who need it, when they need it, and in the format they need it, is a prerequisite for successfully improving the odds of raising creativity (Janz \& Prasarnphanich, 2003; Leonard \& Straus, 1997; Quinn, Anderson, \& Finkelstein, 1996). The urgency of a structured approach to managing the ICT function increases with time, especially as new entrants compete for their share of global markets. Given the rapid acceleration of world market expansion and the strengthening of cross-border ties between firms entering into collaborative agreements to capture a targeted share of these global markets, the imperative of having access to relevant knowledge becomes an absolute necessity (Sanotos, Doz \& Williamson, 2004). The validity of this knowledge is of immense concern to organizations, and is not easily ascertained, verified, protected nor preserved, and is further heightened in an electronic environment that spans continents (Hsai et al., 2006; Okafor \& Osuagwu, 2006; Stahl, 2006).

\section{Constructing a KM / Creativity Model for the MNC}

It may be said that creativity taps into that aspect of knowledge (referred to as tacit), which is difficult to articulate and explain (from the purview of the actor) and which is expressed in innovative thoughts and ideas leading to innovative products, services and processes (Nonaka, 1991; Stenmark, 2000). It is this aspect of knowledge that organizations should foster and support if innovative products, services and processes are to be stimulated and provide the continued competitive value essential for the organization (Brockman \& Morgan, 2003; DeSouza \& Evaristo, 2004; Garvin, 1993). For the multinational firm, as with any organization, the most difficult transfer to achieve is tacit-to-tacit transfer, which is likely to require the greatest social interaction wherein the needed training and mentoring can be provided (Bhatt, 2001). The task is compounded not only by the geographic dispersions but by the differences in cultures, norms, values and even technologies that can obscure and hinder transfer, thereby undermining the creative process and ensuing competitive potential (Bock, Zmud, Kim \& Lee, 2005; Cross et al., 2003; Earley \& Mosakowsi, 2004; Quinn et al., 1996; Scott, 2000; Wasko \& Faraj, 2005).

To quote Zack (2003, p.67) concerning the end product of creative thought,

"Products and services are only what are visible or tangible to customers - they're the tip of the iceberg. But like the iceberg, most of what enables a company to produce anything lies below the surface, hidden within the so-called invisible assets of the organization - its knowledge about what it does, how it does it, and why."

Hult (2003, p. 150) goes on to define knowledge management as,

"the organized and systematic process of generating and disseminating information, and selecting, distilling, and deploying explicit and tacit knowledge to create unique value that can be used to achieve a competitive advantage in the market place by an organization."

The proposed model that follows is an attempt to lay an 'actionable framework' that enables practitioners to wrest these hidden assets in a systematic way so as to extract maximal leverage from their latent potential.

\section{A Proposed Model}

In Nonaka's (1991) well known SECI model (socialization/ externalization/ combination/ internalization) describing the interplay of explicit and tacit knowledge generated, transferred, and recreated in organizations, socialization or transfer of tacit knowledge is viewed in a context of physical proximity often through a mentoring environment, while Cheung \& Kwan (2004) and Hedlund (1994) go far, considering the inter-organizational domain. The model presented here, 
geared as it is to an MNC environment, requires the consideration of virtual mentoring and the supporting technologies that take into account the differences in culture, language, modes of operation, and so forth; notions supported by Davy (2006), Holsapple and Joshi (2002), and MullerMerbach (2006). Both explicit and tacit knowledge need to be exchanged not just vertically within different levels of the organization but also horizontally, cutting across the organization. The dynamic of SECI to transform this tacit / explicit interplay into novel products, services or processes takes on a greater level of complexity and presents a greater challenge for the KM technology needed to support an amorphous, innovative idea within the context of the MNC.

Comprehensive summaries of various KM models and notions of creativity and innovation can be found in Bhatt (2001), Despres and Chauvel (2000), Durant-Law (2006), Fielden and Malcolm (2006), Fischer and Ostwald (2001), Gourlay (2006), Hazlett, McAdam \& Gallagher (2005), Nunamaker, Romano, and Briggs (2001), and McAdam and McCreedy (1999). There has been considerable debate concerning knowledge creation and decision making (Carayannis, 1999; Cheung \& Kwan, 2004; Earl, 2001; Hedlund, 1994; Hsai et al. 2006; Janz \& Prasarnphanich, 2003; Jones, 2006; Nonaka, 1991; Okafor \& Osuagwu, 2006), as distinct from innovative idea creation generated from that knowledge, the focus of the model presented here. The foci of these various other researchers, therefore, tends to be on acquisition, transfer, sharing and storing of knowledge, regardless of the differences in nomenclature used to describe these constructs. Less attention has been on the transformation of that knowledge or that spark or moment of inspiration that precedes all of this, but is nonetheless intertwined with this process. Also missing from their considerations is that aspect wherein semi-articulated ideas which are still too immature / naïve to be entirely made explicit for the purpose of implementation are nonetheless still consciously or unconsciously part of the brainstorming activity.

Torrellas (2002) warns there is a tendency to assume that knowledge is unproblematic, predefined, and pre-packaged, which in effect underestimates the tacit knowledge dimension. The model proposed here recognizes the three myths he identifies: KM technology can deliver the right information to the right person in the right time, can store human intelligence and experience, and can distribute human intelligence. It is this area of the tacit innovative idea creation process that the proposed model attempts to tease out, that 'real' knowledge that 'exists between the ears' (Okafor \& Osuagwu, 2006), which these authors acknowledge is difficult to articulate, codify and automate. Like Jones (2006), our model recognizes and emphasizes the learning achievable from consideration, analysis and archiving of successes and failures and their contribution to this 'knowledge between the ears'. Additionally, that serendipitous discovery that is part of creative thought, and the managerial oversight and technological supports which can either hinder or foster the realization of these moments of brilliance, are considered within the context of the challenges of an MNC environment (Holsapple \& Joshi, 2001; Krogstie, Sindre \& Jorgensen, 2006).

The model proposes three distinct idea regions. As shown in Figure 1, these areas each serve unique functions and do not overlap. They are identified, with appropriate supporting KM resources, and defined as follows:

\section{Tacit knowledge zone (TKZ)}

In this zone, knowledge exists, but not in any structured or codified format. An idea is sparked and the ingenuity of the individual responsible for conceptualizing the product, event, or service relies on intuition and knowledge obtainable both from inside and outside the firm, input from others, and the random sparking of additional ideas that may occur as the primordial mix of tacit knowledge causes the idea to take shape. 


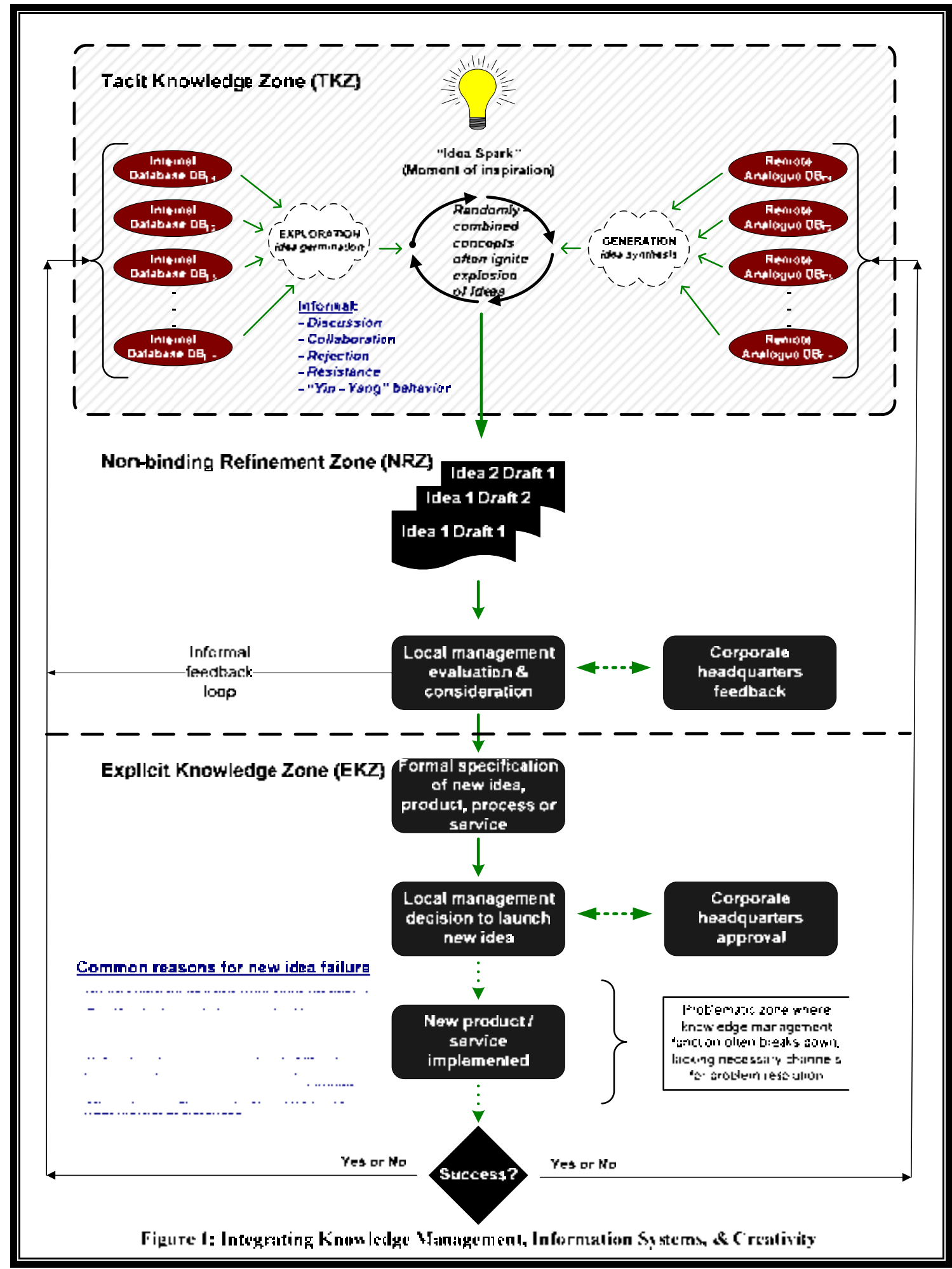

The process - like all ingenious modes of revelation - begins with a spark of an idea, a moment of inspiration, or whatever magic occurs when a vision pops into one's mind for a product, service or process that may be lacking in local (or global) markets. This is the first element of the TKZ. It is virtually impossible to predict when these inspired moments occur and even more confounding 
to attempt to automate them, tempting as that may be. Yet, by providing access to as much information as today's knowledge worker needs, the ability of the firm to maintain some reasonable expectation that product designers will continue to envision novel concepts is critical for the MNC. By formalizing the various aspects associated with dispensing information and knowledge throughout the company (with additional system features such as security, reliability, and performance in mind), those firms that allow the freedom of data to radiate throughout the enterprise are more likely to foster idea creation than those who do not (Ergazakis et al., 2006).

A second critical element present in the TKZ is the notion of idea germination. Within the confines of the proposed model, idea germination refers to a mode of exploration involving empirical research on complex, dynamic, multi-node datasets distributed throughout the firm, combined with traditional and non-traditional methods of analyzing how this information influences new product design and/or service concepts. In this early phase of the creativity framework, knowledge takes on a tacit aspect; that is, knowledge becomes somewhat inarticulate. For example, the 3M Industrial Designer working in the Adhesives Division knew much about the adhesive composites he helped produce but could not articulate where the results of his experimentation with the adhesive would lead. It took the imagination of another $3 \mathrm{M}$ worker to realize its potential by using the non-residual sticky glue on paper notes around his office at $3 \mathrm{M}$. Within several months of internal use, its utility became apparent when $3 \mathrm{M}$ product designers launched the Post-it ${ }^{\circledR}$ notes product line, yielding millions of profit dollars for the firm (Bartlett \& Mohammed, 1995).

To aid in this early phase of exploration, the computer software industry has made huge leaps in producing business intelligence software designed specifically to aid in the flow of information throughout the firm and to allow users to examine data (from diverse manufacturers) from various perspectives to complement and drive tacit knowledge flow present in all firms. Such useful information may also be found in local internal databases that could impart significant benefit to a wide user audience rather than being locked away in arcane databases spread throughout the organization and beyond the reach of users who might otherwise benefit from having access to this information. These internal databases are denoted in the figure as $\mathrm{DB}_{\mathrm{L} 1}, \mathrm{DB}_{\mathrm{L} 2}, \ldots \mathrm{DB}_{\mathrm{Ln}}$ (' $\mathrm{L}$ ' for local). Several important questions arise - Is all pertinent data available to individuals and groups involved with new product ideas? Is there a methodology in place to drive this relevant data into the hands of those who need it? Who decides what data gets shared and what data becomes unavailable? And when?

Idea synthesis, a third prerequisite of the idea generation process - draws from a wide array of analogous cases external to the business. These cases may be known by insiders within a region, industry, nation, or even globally. One such example of a company whose approach to retailing is legendary is Wal-Mart, a firm held in the highest regard by industry experts, not only for driving 2005 revenues ( $\$ 353.6$ billion) greater than the combined 2005 revenues of Apple Computer ( $\$ 13.9$ billion), Cisco ( $\$ 24.8$ billion), Corning (\$4.6 billion), Dell (\$49.2 billion), HewlettPackard ( $\$ 86.7$ billion), IBM (\$91.1 billion), Microsoft ( $\$ 39.7$ billion), Motorola ( $\$ 36.5$ billion), and Starbucks Corp. ( $\$ 6.4$ billion) but also because of the firm's operational dexterity in using ICT in every aspect of its operations. The ability of other firms to mimic Wal-Mart's approach to leveraging ICT in ways similar to those used by the celebrated retailer is relatively straightforward, since so much secondary data is available from external sources. However, the implementation of such imitation is often where the formula breaks down.

The ability to draw from these secondary data sets and generate ideas may enhance a firm's potential for success and is especially useful and requires, of course, that access to this external data is not only available but is frequently accessed by users sifting for inspiring bits of relevant data. These external or foreign databases are denoted in the figure as $\mathrm{DB}_{\mathrm{F} 1}, \mathrm{DB}_{\mathrm{F} 2}, \ldots \mathrm{DB}_{\mathrm{Fn}}$ (' $\mathrm{F}$ ' for foreign) and help to stimulate novel solutions to ideas that may emanate from remote associations 
with the knowledge gleaned from these data sets or from related information that might be loosely tied to new concepts and ideas.

Logically following the remote associations drawn by idea innovator(s), a continual process of evaluation follows the concept from inception to implementation. Expert knowledge plays a significant role in the evaluation process since it is the yardstick against which the degree of goodness (or fit) is assessed, which will only be as good as the willingness and accuracy with which the expert shares this knowledge, often being less forthcoming and able to articulate the "unusual" in their knowledge domain (Okafor \& Osuagwu, 2006). Underpinning each of these steps in the idea creation process is the dependency on ICT and the data stored within. The distribution, accessibility, and integrity of the data repositories are major influences in determining the probability of successfully launching an idea or concept (Edmonds \& Candy, 2002).

It may also be useful to imply that a highly cognitive, supportive system should take into account "visualization" and "knowledge" aspects of the business domain (e.g., operations, marketing, sales, etc.) to foster the formation of some of the ingredients of creative work. The modeling of these factors, through subsequent analysis that incorporates tangible and intangible benefits, costs, and risks, would result in conveying the requirements necessary to sustain cognitive and productive output.

Before leaving the TKZ, the new idea goes through a series of iterations and coalesces into a rough outline of its final form. The rapidity and fluidity of the knowledge revolving inside this zone is such that the information flow follows no rules and is unbounded in content. Leveraging input from knowledge stored internal and external to the firm in a series of informal discussions and collaborations in a sort of "yin-yang" fashion by participants who either accept or reject the proposed idea yields invaluable critiques and suggestions for improvement that often leads to positive outcomes.

Ultimately the point is reached where a semblance of a product or service specification begins to take shape, at which juncture this rough draft may be passed onto management or onto other specialized groups to help further develop the idea

\section{Non-binding refinement zone (NRZ)}

This zone is best characterized as the area wherein problems associated with the idea or concept become marginalized using input from formal internal feedback loops. The application of additional knowledge in this zone improves the initial idea - which begins to congeal and becomes more structured - but not necessarily ordered into some methodical or otherwise codified format. Also, version control and managerial oversight of the evolving idea may or may not be present and/or needed.

As it enters into the NRZ, the idea proposal begins to take shape and is formally presented for consideration and evaluation by local management. Hopefully, the local management team passes the idea onto a receptive executive sponsor at the headquarters location, whose optimal reactions include providing feedback to the local management team concerning the product's positioning, pricing, desired features, and so on. It is the local management's responsibility to do whatever it can to promote or reject the idea with a clear explanation as to why it suggests the stated course of action. The feedback loop that translates these sentiments and consultative suggestions feeds (ideally) a local database that tracks the various machinations, iterations, and managerial feedback and streamlines the process for channeling information between the two zones. After numerous repetitions of refinement steps, a formal specification is fed into the third zone. 


\section{Explicit knowledge zone (EKZ)}

In this zone, the biggest threat for failing to realize full potential of the idea becomes manifest; though product guidelines and specifications are drawn, problems with implementation often occur. This zone clearly needs a formal methodology to foster idea refinement and problem resolution and for new product design - preparation, marketing, pricing, and launching.

In the EKZ, the formalized product specification is accepted by local management for implementation and product launch. Here too, the channel between corporate headquarters and the local subsidiary should be unambiguous and support for the project should be sought from executives at the headquarters location. By involving top management, an opportunity for collecting information about how the progression of the idea evolved - from exploration and generation to its ultimate design - provides the firm the opportunity to keep a watchful eye on the product idea pipeline as it and other ideas evolve.

Ironically, there is little formal attention paid to capturing this valuable knowledge in many firms and, consequently, the product often does not fully meet its potential, materializing in failures after launch. These shortcomings may be due, in part, to the absence of a formal methodology implemented by the organization to secure such purposeful information. As a result, there is no opportunity to learn from prior mistakes and much-needed knowledge about the tastes and preferences of local markets becomes lost, misunderstood or misinterpreted. This lax condition raises the possibility of producing catastrophic consequences, as came to pass when the Yugo and Renault automobiles were pulled from the U.S. market after miserable sales results resulting from a serious lack of understanding the American consumer.

The entire process of idea sponsorship is characterized by a feedback mechanism similar to those posited by Fischer and Ostwald, 2001, Holsapple and Joshi (2002), Hsai et al. (2006), and McAdam and McCreed (1999), which passes on information about how well the market received the new products, services or processes, noting successes or failures, all captured and accessible via databases, and providing reasons for these outcomes.

\section{Factors Intrinsic to the Model}

While easy to conceptualize, the practice of implementing a tightly-coupled IS architecture aiding the creative process is not a simple endeavor. Problems often arise, firstly, when logically linking physically distributed workers in a firm. Operating in regional information silos, affected by personal information spheres, influenced by differing cultures, contexts, norms, etc., distributed data may not accurately reflect the original content of the originator (Bhatt, 2001; Earley \& Mosakowsi, 2004). Also, a firm may interlink its far-flung operational centers and be falsely lulled into thinking that the firm has the ability to distribute not only transactional data, but information and even knowledge throughout this interlinked mesh. Here too, information workers run the risk of not properly conveying the meaning of information across borders. Consider, for example, the notion of color used in web pages and computing applications. To a western developer tabulating a column of debits and credits for example, often the net result is indicated using a green or red background to signify either a positive or negative outcome (think of the term: "operating in the red / green"). Outside the western sphere of culture, colors have quite different connotations. In some African nations, red is felt to be blasphemous yet considered to indicate wealth or luxury in others (Ricks, 2006). Hence a multinational firm maybe physically linked but logically disconnected (Hsai et al., 2006). Of course the classic example that comes to mind when discussing international blunders is the oft-cited tale of the Chevrolet Nova automobile that was produced during the mid-1960s in North America. Introduced by General Motors, the car was a smashing success in the domestic market and the firm quickly decided to take advantage of the sales and marketing momentum that had developed momentum after the car's introduction (Morrison \& 
Conaway, 1998). Upon introducing the auto into Latin America, sales were virtually zero. It took some time before the Latin American GM executives explained to U.S. executives that the probable cause of failure was linked to the car's name - Nova - similar to the Spanish term "no va", meaning "no go".

A second issue not explicit in the model relates to pricing. With so many nations joining the race toward globalizing their economies, the off-shore manufacturing that we are now witnessing is causing product life cycles to shrink drastically. Customers have become much more savvy and demanding, and the rise of dominant global competitors emerging in most markets means that many companies are forced to compete on price - a strategy of last resort. As such, pricing the perceived value of new products and services becomes more problematic as pricing for new products and services occur faster than ever. Hence, no input mechanism is provided in the model that takes into consideration the important aspects associated with pricing. Fortunately however, advances in market research and their availability somewhat lessen the task of dynamic product pricing.

Finally, the third (but certainly not the last or least) issue not specifically addressed in the discussion of the model involves security. Knowledge management is about forming an efficient methodology for systematically gathering, organizing, and disseminating information. It essentially consists of processes and tools to effectively capture and share data as well as its use individuals within an organization. The problem with formalized (i.e., 'rigid') knowledge management systems, however, is that they promote sharing information and often do not follow dynamic security precautions to prevent unauthorized users from accessing sensitive data. While methods such as authentication or passwords, cryptography programs, intrusion detection systems or access control systems are available, many end users are not trained adequately to properly take advantage of them or to even appreciate the sensitivity of the data they handle.

These issues and the peripheral topics of malicious employees, infrastructure and idea ownership and protection, the appropriate techniques to use when architecting an idea refinement environment and the enforcement policies attributed to safeguarding the KM process (Okafor \& Osuagwu, 2006; Stahl, 2006) must necessarily be considered in the context of the model but are reserved for a future paper.

\section{Further Research}

The model proposed in this paper provides a framework for research in which to examine the current status and adequacy of the KM function extant among MNCs and the appropriateness for its adoption for firms eager to enhance their ability to be creative and innovative. Answers to questions stemming from the model that will prove useful and ultimately point to a 'best practices' approach include:

What are the KM resources being used by MNCs to support the various knowledge zones identified in their creative processes?

Are these resources deployed similarly among US-owned firms, Asian-based firms, and European-based firms?

Do the returns from these investments differ in these regions and if so, how?

Numerous other questions remain as firms extend themselves globally:

Is there a concomitant expansion of the firms' ability to handle increased amounts of knowledge as it expands into foreign territories?

How exactly does this increased knowledge help or hinder the creativity process? 
How are these creative processes best supported technologically?

\section{Conclusion}

Ever since the world watched as the Internet made possible the frenzy of global business and the increasingly complicated web of interdependencies among and between nation states, the possibility for the multinational to leverage the seemingly inexhaustible potential of information technology has relentlessly continued. From a domestic perspective, U.S. companies since 2001 have been posting record profits and watching their equity values soar as ICT-related business activities such as outsourcing to India and China flourishes (Gabberty 2004). From the international view, China has evolved from a third-world status to that of a serious 'online player' in the global economy and has vast potential for continued successes using advances in ICT. Still, other nations such as Japan that cling to a historically isolated past, watch from the sidelines as China's foray into establishing itself as a manufacturing juggernaut pose a serious threat to the juggernaut that once was Japan.

Extended research is needed to understand the effects of globalization as history unfolds both from the perspective of the multinational and its operational objectives and from the consumer viewpoint concerning convergence of world tastes. As proposed in the model presented here, this needs to take place in the context of maintaining a rigorous and complete set of automated knowledge around which all of this business activity is made possible.

\section{References}

Barry, F. \& Kearney, C. (2006). MNEs and industrial structure in host countries: A portfolio analysis of Irish manufacturing. Journal of International Business Studies, 37(3), 392-407.

Bartlett, C.A. \& Mohammed, A. A. (1995). 3M: Profile of an Innovating Company. ,Harvard Business School Case 395-016.

Bhatt, G.D. (2001). Knowledge management in organizations: Examining the interaction between technologies, techniques, and people. Journal of Knowledge Management, 5(1), 68-75.

Bock, G-W., Zmud, R.W., Kim, Y-G., \& Lee, J-N. (2005). Behavioral intention formation in knowledge sharing: Examining the roles of extrinsic motivators, social-psychological forces, and organizational climate. MIS Quarterly, Special Issue on Information Technologies and Knowledge Management, 29(1), 87-111.

Brockman, B.K. \& Morgan, R.M. (2003). The role of existing knowledge in new product innovativeness and performance. Decision Sciences, 34(2), 385-419.

Cairncross, F. (2002, May). Knowledge, decision making, and innovation. Harvard Business Review, 2346.

Carayannis, E.G. (1999). Fostering synergies between information technology and managerial and organizational cognition: The role of knowledge management. Technovation, 19, 219-231.

Cheung, P-K. \& Kwan, M.M. (2004, August). Towards a unified framework on knowledge sharing: An organizational knowledge management perspective. Proceedings of the Tenth Americas Conference on Information Systems, 2295-2304.

Cross, R., Davenport, T.H., \& Cantrell, S. (2003, Fall). The social side of performance. MIT Sloan Management Review, 20-22.

Darroch, J. \& McNaughton, R. (2002). Examining the link between knowledge management practices and types of innovation. Journal of Intellectual Capital, 3(3), 210-222.

Davy, C. (2006, February). Recipients: The key to information transfer. Knowledge Management Research \& Practice, 4(1), 17-25. 
De Souza, K.C. \& Evaristo, J.R. (2004). Managing knowledge in distributed projects. Communications of the ACM, 47(4), 87-91.

Despres, C. \& Chauvel, D. (2000). A thematic analysis of the thinking in knowledge management. In C. Despres \& D. Chauvel, (Eds.), Knowledge horizons: The present and the promise of knowledge management (pp. 55-86). Boston: Butterworth-Heinemann.

Durant-Law, G. (2006). Knowledge models. Retrieved October 7, 2006 from http://www.durantlaw.info/knowledge models.htm

Earl, M. (2001, Summer). Knowledge management strategies: Toward a taxonomy. Journal of Management Information Systems, 18(1), 215-233.

Earley, P.C. \& Mosakowsi, E. (2004, October). Cultural intelligence. Harvard Business Review, 139-146.

Edmonds, E. \& Candy, L. (2002). Creativity, art practice, and knowledge. Communications of the ACM, 45(10), 91-95.

Ergazakis, K., Metaxiotis, K., \& Psarras, J. (2006, February). A coherent framework for building successful $\mathrm{KCs}$ in the context of the knowledge-based economy. Knowledge Management Research \& Practice, $4(1), 46-59$.

Farrell, D. (2006). Smarter off-shoring. Harvard Business Review, 84(6), 84-98.

Fielden, K. \& Malcolm, P. (2006). Bounded innovation management: Mapping the patterns of innovation in a small software development organization. Journal of Information, Information Technology, and Organization, 1, 1-20.

Fischer, G. \& Ostwald, J. (2001, January/February). Knowledge management: Problems, promises, realities, and challenges. IEEE Intelligent Systems, 60-72.

Ford, D.P. \& Staples, D.S. (2006). Perceived value of knowledge: the potential informer's perception. Knowledge Management Research \& Practice, 4, 3-16.

Gabberty, J. (2004). Revving the innovation engine in China, Japan, and the United States. Innovation: Management, Policy \& Practice, 6(1), 78-86.

Garvin, D.A. (1993, July-August). Building a learning organization. Harvard Business Review on Knowledge Management, 47-80.

Gourlay, S. (2006, February). Towards conceptual clarity for 'tacit knowledge': A review of empirical studies. Knowledge Management Research \& Practice, 4(1), 60-69.

Hazlett, S-A., McAdam, R., and Gallagher, S. (2005, March). Theory building in knowledge management in search of paradigms. Journal of Management Inquiry, 14(1), 31-42.

Hedlund, G. (1994, Spring). A model of knowledge management and the N-Form corporation. Strategic Management Journal, 73-90.

Hill, J, S., Marino, L. D., \& Chae, M-S. (2003). Global industry profiling: Machine tool industry. The Multinational Business Review, 11(1), 89-101.

Holsapple, C.W. \& Joshi, K.D. (2002). Knowledge management: A threefold framework. The Information Society, 18, 47-64.

Hsai, T-L., Lin L-M., Wu J-H. \& Tsai H-T. (2006). A framework for designing nursing knowledge management systems. Interdisciplinary Journal of Information, Knowledge, and Management, 1.

Hult, G.T.M. (2003). An integration of thoughts on knowledge management. Decision Sciences, 34(2), 189-195.

Janz, B.D. \& Prasarnphanich, P. (2003). Understanding the antecedents of effective knowledge management: The importance of a knowledge-centered culture. Decision Sciences, 34(2), 351-384.

Jones, K. (2006, Summer). Knowledge management as a foundation for decision support systems. Journal of Computer Information Systems, 116-124. 
Kim, D., Cavusgil, T.S., \& Calantone, R.J. (2006). Information systems innovations and supply chain management: Channel relationships and firm performance. Journal of Academy of Marketing Science, 34(1), 40-54.

Klein, L. (2003). The use of the input-output tables to estimate the productivity of ICT. Journal of Policy Modeling, 25(5), 471-480.

Knight, G.A. \& Cavusgil, S.T. (2004). Innovation, organizational capabilities, and the born-global firm. Journal of International Business Studies, 35(2), 182-207.

Kogut, B. \& Zander, U. (2004). Knowledge of the firm and the evolutionary theory of the multinational corporation. Journal of International Business Studies, 35(2), 175-211.

Krogstie, J., Sindre, G. \& Jorgensen, H. (2006). Process models representing knowledge for action: A revised quality framework. European Journal of Information Systems, 15, 91-102.

Kuei, C-H, Madu, C.N., Chow, W.S., \& Lu, M.H. (2005). Supply chain quality and excellence in the new economy: An empirical study of Hong Kong based firms, The Multinational Business Review, 13(1), 33-55.

Leonard, D. \& Straus, S. (1997, July-August). Putting your company's whole brain to work, Harvard Business Review on Knowledge Management, 109-136.

Liker, J.K. \& Morgan, J.M. (2006). The Toyota way in services: The case of lean product development. The Academy of Management Perspectives, 20(2), 5-20.

McAdam, R. \& McCreedy, S. (1999). A critical review of knowledge management models. The Learning Organization, 6(3), 91-100.

Morrison, T. \& Conaway, W.A. (1998). Bite the wax tadpole. Industry Week, 46 - 48.

Muller-Merbach, H. (2006, February). Three kinds of knowledge, reflecting Kant's three kinds of action. Knowledge Management Research \& Practice, 4(1), 73-74.

Nonaka, I. (1991, November-December). The knowledge-creating company. Harvard Business Review, 2146.

Nunamaker, Jr., J.F., Romano, Jr., N.C. \& Briggs, R.O. (2001). A framework for collaborative and knowledge management. Proceedings of the 34th IEEE Hawaii International Conference on System Sciences, 1-12.

Okafor, E.C. \& Osuagwu, C.C. (2006). The underlying issues in knowledge elicitation. Interdisciplinary Journal of Information, Knowledge, and Management, 1, 95-107. Retrieved from http://ijikm.org/Volume1/IJIKMv1p095-1070kafor.pdf

Quinn, J.B., Anderson, P. \& Finkelstein, S. (1996, March - April). Managing professional intellect. Harvard Business Review on Knowledge Management, 181-205.

Ricks, D.A (2006) Blunders in international business (4th ed.). Malden, Mass: Blackwell Publishing.

Sanotos, J., Doz, Y. \& Williamson, P. (2004). Is your innovation process global? MIT Sloan Management Review, 45(4), 31-37.

Scott, J. E. (2000). Facilitating inter-organizational learning with information technology. Journal of Management Information Systems, 17(2), 81-113.

Stahl, B.C. (2006). On the difference or equality of information, misinformation, and disinformation: A critical research perspective. Informing Science Journal, 9, 83-96. Retrieved from http://inform.nu/Articles/Vol9/v9p083-096Stahl65.pdf

Stenmark, D. (2000). Leveraging tacit organizational knowledge. Journal of Management Information Systems, 17(3), 9-24. 
Torrellas, G.A.S. (2002). A framework for learning model innovation using knowledge engineering. In Proceedings of the IASTED International Conference on Information and Knowledge Sharing; 18-20 November 2002; St. Thomas, U.S. Virgin Islands, pp. 32-38.

Wasko, M.M. \& Faraj, S. (2005). Why should I share? Examining social capital and knowledge contribution in electronic networks of practice. MIS Quarterly, Special Issue on Information Technologies and Knowledge Management, 29(1), 35-57.

Zack, M.H. (2003, Summer). Rethinking the knowledge-based organization. MIT Sloan Management Review, 67-71.

\section{Biographies}

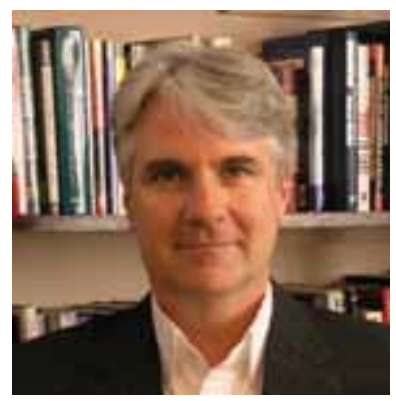

James W. Gabberty, D.P.S., M.S., M.B.A. Prior to accepting an Associate Professorship at the Pace University Ivan G. Seidenberg School of Computer Science and Information Systems, Dr. Gabberty worked as an ICT practitioner for more than twenty years in New York City's financial community at Fortune 100 firms. He is an avid author of many ICT, macroeconomic and marketing articles and is particularly interested in the impact that technology has on society and the competitiveness of domestic firms, multinational corporations and nations. His research interests include knowledge management, international trade, and the strategic and innovative uses of ICT in advancing the competitiveness of firms, regions, and nations. He earned his D.P.S. degree from the Lubin School of Business at Pace University, an M.S. in Telecommunications and Computing Management from Polytechnic University in Brooklyn, NY, and M.B.A. in M.I.S from the New York Institute of Technology. During 2006 he was Scholar-in-Residence at the Stern School of Business at New York University and is a Wilson Faculty Fellow at Pace University.

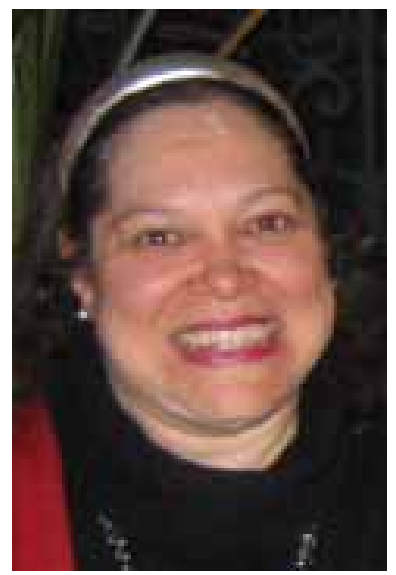

Jennifer D.E. Thomas, Ph.D, M.B.A., is Professor of Information Systems at Pace University in New York City. She received her Ph.D. and M.B.A. from Concordia University in Montreal, Canada. Her research interests include Knowledge Management, Human Factors, Multimedia and the Impact of Technology Integration on Learning. She teaches onsite and online courses at both the graduate and undergraduate levels. 